\title{
The Occurrence of Lipoteichoic Acids in the Membranes of Gram-positive Bacteria
}

\author{
By J. COLEY, M. DUCKWORTH AND J. BADDILEY \\ Microbiological Chemistry Research Laboratory, School of Chemistry, \\ University of Newcastle upon Tyne, Newcastle upon Tyne, NEI $7 R U$
}

\section{(Received 2 May 1972; revised Io August 1972)}

Glycerol teichoic acids have been found associated with the cytoplasmic membrane of all of the Gram-positive bacteria examined and it is believed that, unlike wall teichoic acids which are absent from some organisms, these membrane teichoic acids are characteristically present in all species (for reviews see Archibald, Baddiley \& Blumsom, I968; Baddiley, 1970, 1972). Wall teichoic acid is attached to the peptidoglycan of the wall through its terminal phosphate residue, but although it has been known for some time that membrane teichoic acid is associated with the outer surface of the membrane (Hay, Wicken \& Baddiley, 1963; Shockman \& Slade, I964) the nature of this association has only recently been examined.

Under the acidic conditions usually employed to isolate membrane teichoic acids the linkage with the membrane is hydrolysed and the purified products comprise chains of glycerol phosphate residues to which D-alanine and sometimes glycosyl residues are attached. When disrupted preparations of Bacillus licheniformis or B. subtilis are treated with $80 \%$ $(\mathrm{w} / \mathrm{v})$ aqueous phenol the membrane teichoic acid can be recovered from the aqueous phase (Burger \& Glaser, I964), and it has been suggested that this gentle non-hydrolytic procedure would not disrupt the presumed covalent linkage between teichoic acid and membrane (Archibald et al. 1968). Material extracted in this way was free of much of the protein and nucleic acid of the organism and did not contain wall teichoic acid. A phenol-extracted membrane teichoic acid from Lactobacillus fermenti NCTC 699I has been prepared (Wicken \& Knox, 1970), and it was concluded from the nature of the products of alkaline hydrolysis that the teichoic acid was combined with glycolipid and phospholipid. This complex is antigenic when injected together with Freund's adjuvant into rabbits, whereas the lipid-free teichoic acid (extracted with trichloroacetic acid) is not antigenic (Knox, Hewett \& Wicken, 1970). Similar results have been obtained from other strains of Lactobacillus (Wicken \& Knox, I97I). A lipoteichoic acid has also been isolated from Streptococcus faecalis NCIB 8 I9I in which the teichoic acid, a polymer of 28 to 35 units of glucosylglucosyl (kojibiosyl)glycerol phosphate, is covalently attached through its terminal phosphate to a diglucosyldiglyceride or more probably a phosphatidyl diglucosyldiglyceride (Toon, Brown \& Baddiley, 1972). Thus the combination between teichoic acid and membrane in this organism takes the form of a lipoteichoic acid in which the lipid is a normal membrane component which intercalates with other phospholipids in the bilayer region of the cytoplasmic membrane. As this teichoic acid is the serological group-specific substance of S. faecalis (group D) and is accessible to antiserum in the intact organism, it is concluded that polymer chains in which serological specificity resides must project from the outer surface of the membrane where they participate in the control of bivalent cation concentration (Heptinstall, Archibald \& Baddiley, I970; Hughes, Stow, Hancock \& Baddiley, I97I). We have now examined a range of bacteria and demonstrated in all cases that the membrane teichoic acid is lipoteichoic acid. 


\section{METHODS}

RNase and DNase were obtained from Sigma Chemical Co., St Louis, Missouri, U.S.A. Sepharose 6B and Sephadex G-200 were obtained from Pharmacia Ltd, London.

The following organisms were used: Lactobacillus buchneri $\mathrm{NCIB} 8007$, L. plantarum NIRD cio6, Staphylococcus aureus н (Baddiley, Buchanan, RajBhandary \& Sanderson, 1962), Micrococcus sp. 24 (from Dr A. L. Davison), S. aureus A I (Davison \& Baddiley, I963) and Bacillus subtilis Marburg strain I68 (Hughes, I97I). They were grown in batch cultures under conditions similar to those described previously (Davison \& Baddiley, I963; Shaw \& Baddiley, 1964; Archibald \& Coapes, 197I ; Hughes I97I). Washed bacteria were disrupted in a Braun disintegrator with cooling; walls, unbroken organisms and debris were removed by centrifugation ( $17000 \mathrm{~g}$ for $20 \mathrm{~min}$ ) and the supernatant solution was freeze-dried. The residue was treated twice with chloroform-methanol $(2: \mathrm{I}, \mathrm{v} / \mathrm{v})$ to remove free lipids, dialysed overnight at room temperature and again freeze-dried. The lipoteichoic acids were extracted from the freeze-dried powder by two different methods.

Extraction of lipoteichoic acid with aqueous phenol. The residue was suspended in water and extracted with an equal volume of $80 \%(\mathrm{w} / \mathrm{v})$ aq. phenol at $4{ }^{\circ} \mathrm{C}$ for $40 \mathrm{~min}$. The upper aqueous phase was collected, dialysed as before and incubated at $37^{\circ} \mathrm{C}$ for $\mathrm{I} 2 \mathrm{~h}$ with DNase (from bovine spleen) and RNase (from bovine pancreas) (Io $\mu \mathrm{g} / \mathrm{ml}$ ) in $5 \mathrm{~mm}$-tris buffer, $\mathrm{pH}$ 8 , containing I mM- $\mathrm{MgCl}_{2}$. The aqueous-phenol extraction was then repeated to remove the enzymes and the aqueous layer was freeze-dried. At least $95 \%$ of the phosphorus in the chloroform-methanol-washed material was extracted into the aqueous phase in the initial phenol treatment and no lipids containing glycerol residues were detected in the phenol phase.

Extraction of lipoteichoic acid by an aqueous procedure. The freeze-dried powder was suspended in distilled water ( $10 \mathrm{mg} / \mathrm{ml}$ ) and boiled gently for $30 \mathrm{~min}$. The solution was then filtered and the filtrate collected. The residue was extracted twice with boiling water under the same conditions. The filtrates were combined, dialysed and freeze-dried. At least $95 \%$ of the total phosphorus was solubilized using this procedure.

Methods for paper and thin-layer chromatography, hydrolysis of fractions and characterization of hydrolysis products were similar to those used in previous studies (Toon et al. I972).

\section{RESULTS AND DISCUSSION}

Lipoteichoic acids extracted by aqueous phenol were purified by chromatography on columns $(25 \mathrm{~mm} \times 450 \mathrm{~mm})$ of Sepharose $6 \mathrm{~B}$ using upward flow $(\mathrm{I} 5 \mathrm{ml} / \mathrm{h})$ with $0.02 \mathrm{M}$ ammonium acetate containing $0.1 \%$ of sodium azide as eluant. The elution diagrams were of three types (Fig. I); type A for Lactobacillus buchneri, L. plantarum, Staphylococcus aureus $\mathbf{H}$ and S. aureus A I; type B for Bacillus subtilis; type C for Micrococcus sp 24. In all cases peak I occurred in the void volume and represented the lipoteichoic acid; the molecular ratio glycerol/phosphorus was $\mathrm{I}: \mathrm{I}$, but differences were noted in the amount and nature of the glycosyl substitution. Peak 2 represented an unidentified polymer containing glycerol, phosphorus and lipid, and peak 3 represented nucleic acid (from extinction at $260 \mathrm{~nm}$ ). Occasionally a small peak showing extinction at $260 \mathrm{~nm}$ was seen before the lipoteichoic acid; this was due to light scattering from colloidal material originally present in the Sepharose. This small peak is similar to that eluted before the lipoteichoic acid from Streptococcus faecalis on Sepharose 6B (Toon et al. 1972) and is presumably an artefact.

The lipoteichoic acids extracted by aqueous phenol resembled in their physical properties 

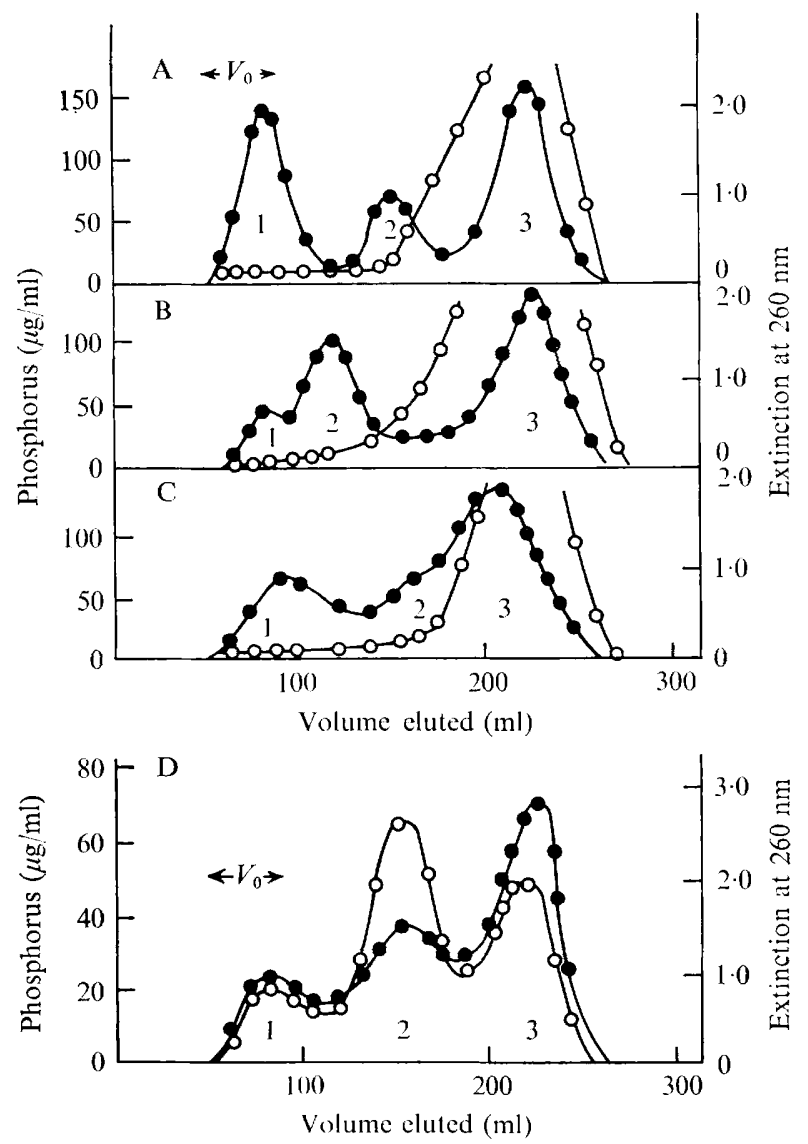

Fig. I. Chromatography of extracts of bacteria on Sepharose $6 \mathrm{~B}$ using 0.02M-ammonium acetate containing $0.1 \%$ sodium azide as eluant. Phenol extracts were used for A, B and C while an aqueous extract was applied in D.A represents extracts of Staphylococcus aureus $\mathrm{H}$ although $S$. aureus AI, Lactobacillus buchneri and L. plantarum gave the same type of separation; B, Bacillus subtilis and $\mathrm{C}$, Micrococcus sp. 24; $\mathrm{D}$ is the elution diagram for $S$. aureus $\mathrm{H}$, although all of the aqueous extracts used in this study gave similar elution curves.

that isolated from Streptococcus faecalis (Toon et al. 1972). They gave very sharp peaks in the ultracentrifuge (6 to Io s) due to the formation of micelles. Hydrolysis in alkali (Io $\mathrm{mg}$ samples in $5 \mathrm{ml}$ of $0 . \mathrm{I} \mathrm{M}-\mathrm{NaOH}$ at $100{ }^{\circ} \mathrm{C}$ for I h) and preparation of methyl esters of the resulting fatty acids followed by gas chromatography showed that fatty acid ester residues (mainly $\mathrm{C}_{16}$, with smaller amounts of $\mathrm{C}_{12}, \mathrm{C}_{14}$ and $\mathrm{C}_{18}$ ) were present; the lipoteichoic acid from Micrococcus sp. 24 contained fatty acid:phosphate in the molecular ratio $1: 14: 3$. The ester residues could not be removed by repeated chromatography on columns ( $16 \mathrm{~mm} \times 250$ $\mathrm{mm}$ ) of Sephadex G-200 using upward flow ( $15 \mathrm{ml} / \mathrm{h}$ ) with sodium dodecyl sulphate solution $(\mathrm{I} \%, \mathrm{w} / \mathrm{v})$ or $6 \mathrm{M}$-urea as eluant. In both these systems the lipoteichoic acids were eluted from the column just after the void volume. This and their stability to chloroform-methanol $(2: \mathrm{I}, \mathrm{v} / \mathrm{v})$ indicates that the lipid and teichoic acid components are not held together by hydrogen bonds, electrovalent attraction or hydrophobic interactions. Fatty acid esters in similar proportions were also detected in material corresponding to peak 2.

Phosphate esters are converted to alcohols by anionic displacement through the action of $60 \%$ (w/v) $\mathrm{HF}$ at $0{ }^{\circ} \mathrm{C}$ for $6 \mathrm{~h}$. Under these conditions neither glycosidic linkages nor fatty 
acid ester linkages are hydrolysed (Glaser \& Burger, 1964), and with the lipoteichoic acid from Streptococcus faecalis the products from such treatment were glycosides of glycerol (from the teichoic chain) together with diglucosyldiglyceride and diglyceride (from phosphatidyl glycolipid) (Toon et al. 1972). The products obtained by treatment of material corresponding to peak 1 with HF were extracted with chloroform and examined by thinlayer chromatography on silica gel (chloroform-methanol-water, $65: 25: 4$, by vol.). Using the periodate-Schiff spray reagents for polyols and glycosides spots corresponding to diglycosyldiglycerides were observed from the lipoteichoic acid from Lactobacillus buchneri, L. plantarum, Staphylococcus aureus AI and S. aureus H. These products were indistinguishable from the corresponding material prepared from lipids extracted from isolated membranes by chloroform-methanol (2:I), but the presence of diglyceride in the lipid extracts after HF treatment has not yet been established unequivocally.

The lipids obtained by the action of HF on the lipoteichoic acids from Bacillus subtilis and Micrococcus sp. 24 differed in their behaviour on thin-layer chromatography from the products of action of HF on the lipids that were extracted from the membranes of these organisms with chloroform-methanol. The reasons for these differences are unknown; nevertheless as these lipoteichoic acids also give fatty acids on treatment with alkali it seems probable that they have a general structural similarity to those obtained from other bacteria.

All the preparations of lipoteichoic acids extracted by aqueous phenol contained small amounts of protein $(0.5$ to $3.0 \%$ ) after the first chromatographic purification, but after repeated purification on columns of Sepharose $6 \mathrm{~B}$ this protein was separated from the lipoteichoic acid.

The lipoteichoic acid preparations extracted by the aqueous procedure were also purified by chromatography on Sepharose $6 \mathrm{~B}$, using the conditions already described. For each species studied the elution diagram was the same (Fig. I D). Three peaks corresponding to phosphate were obtained similar to those observed with the phenol extraction procedure. However, the separation of material showing extinction at $260 \mathrm{~nm}$ was different from that in the phenol extracts. The lipoteichoic acid fraction (Fig. I D, peak I) contained 30 to $40 \%$ (w/w) of protein together with RNA and DNA. The nucleic acids and protein could be removed almost completely by digestion with pronase, DNase and RNase followed by chromatography. Although losses on extraction and purification were considerable the purified lipoteichoic acid represented about $2.0 \%$ of the dry weight of Micrococcus sp. 24 after removal of walls and cell debris. Ultracentrifugation of the lipoteichoic acid fraction obtained by aqueous extraction and chromatography did not show a sharp peak corresponding to a micelle. On the other hand, phenol-extracted lipoteichoic acids (Fig. I ABC, Peak I) were prepared virtually free of protein and these preparations gave very sharp peaks in the ultracentrifuge. We conclude that, although it is unlikely that lipoteichoic acid is covalently attached to either protein or nucleic acids, these molecules nevertheless profoundly influence their physical properties, especially with respect to micelle formation.

The present and previous work shows that lipoteichoic acids are widespread components of the membrane of Gram-positive bacteria and, taken together with the more extensive surveys of the occurrence of membrane teichoic acids, it is likely that they are present in all cases. In the organisms examined here no evidence was obtained for the occurrence of free membrane teichoic acid and so, as was shown for Streptococcus faecalis, it is likely that all membrane teichoic acid is in the form of lipoteichoic acid.

We thank the Science Research Council for financial assistance and for a studentship (to J. C.). 


\section{REFERENCES}

Archibald, A. R., Baddiley, J. \& Blumsom, N. L. (1968). The teichoic acids. Advances in Enzymology 30, 223-253.

Archibald, A. R. \& Coapes, H. E. (I97I). The wall teichoic acid of Lactobacillus plantarum NIRD cio6. Biochemical Journal 124, 444-460.

Baddiley, J. (1970). Structure, biosynthesis anad function of teichoic acids. Accounts of Chemical Research 3, $98-103$.

Baddiley, J. (1972). Teichoic acids in cell walls and membranes of bacteria. In Essays in Biochemistry, vol. 8. Edited by P. N. Campbell and F. Dickens. London: Academic Press. (in the press).

Baddiley, J., Buchanan, J. G., RajBhandary, U. L. \& Sanderson, A. R. (1962). Teichoic acid from Staphylococcus aureus $\mathrm{H}$. Structure of the $N$-acetylglucosaminyl-ribitol residues. Biochemical Journal $\mathbf{8 2}$, 439-448.

Burger, M. M. \& Glaser, L. (I964). The synthesis of teichoic acids. I. Polyglycerol-phosphate. Journal of Biological Chemistry 239, 3168-3177.

Davison, A. L. \& Baddiley, J. (I963). The distribution of teichoic acids in staphylococci. Journal of General Microbiology 32, 27I-276.

Glaser, L. \& Burger, M. M. (I964). The synthesis of teichoic acids. III. Glucosylation of polyglycerolphosphate. Journal of Biological Chemistry 239, 3187-3191.

HAY, J. B., WICKEN, A. J. \& BADDILEY, J. (1963). The location of intracellular teichoic acids. Biochimica et biophysica acta 7I, 188-190.

Heptinstall, S., Archibald, A. R. \& Baddiley, J. (I970). Teichoic acids and membrane function in bacteria. Nature, London 225, 519-521.

Hughes, A. H., Stow, M., Hancock, I. C. \& Baddiley, J. (I97I). Function of teichoic acids and effect of novobiocin on control of $\mathrm{Mg}^{2+}$ at the bacterial membrane. Nature New Biology 229, 53-55.

Hughes, R. C. (197I). Autolysis of isolated cell walls of Bacillus licheniformis NCTC 6346 and Bacillus subtilis Marburg strain I68. Biochemical Journal I19, 849-860.

Knox, K. W., Hewett, M. J. \& WICKen, A. J. (1970). Studies on the group F antigen of lactobacilli: antigenicity and serological specificity of teichoic acid preparations. Journal of General Microbiology 6o, 303-313.

Shaw, N. \& Baddiley, J. (1964). The teichoic acid from the walls of Lactobacillus buchneri NCIB 8007. Biochemical Journal 93, 317-32I.

Shockman, G. D. \& Slade, H. D. (I964). The cellular location of the streptococcal group D antigen. Journal of General Microbiology 37, 297-305.

Toon, P., Brown, P. E. \& Baddiley, J. (1972). The lipid-teichoic acid complex in the cytoplasmic membrane of Streptococcus faecalis NCIB 8191. Biochemical Journal 127, 399-409.

Wicken, A. J. \& KNOX, K. W. (1970). Studies on the group F antigen of lactobacilli: isolation of a teichoic acid-complex from Lactobacillus fermenti NCTC 699I. Journal of General Microbiology 60, 293-302.

Wicken, A. J. \& Knox, K. W. (I97I). A serological comparison of the membrane teichoic acids from lactobacilli of different serological groups. Journal of General Microbiology 67, 25I-254. 